Military Technical College

Kobry El-Kobbah, Cairo, Egypt

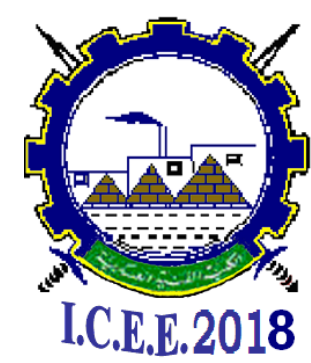

$9^{\text {th }}$ International Conference on

Chemical \& Environmental

Engineering

3-5 April 2018

DFI-3

\title{
Development of Novel and Cost Effective Techniques for Purification of Commercial Grade Phosphoric Acid for Fertilizers, Food and Pharmaceutical Industries
}

\author{
By
}

\author{
H. M. Abdel-Ghafar1*, E. A. Abdel-Aal1, H. El-Shall2, M.A.M. Ibrahim3 and A.K. Ismail1
}

\begin{abstract}
Cultivation of 1.5 millions Faddens is one of the major projects for securing food supply to the ever increasing population; therefore, expansion of the fertilizer industry becomes a must. Phosphate ores from New Valley and Nile Valley are chemically processed by sulphuric acid to produce phosphoric acid intermediate by the dihydrate process. Two plants are already in operation at "Abu Zabaal" and "Fayoum" and another two plants are under establishment, one along the Red Sea Coast at El-Sokhna and the other at the "New Valley". Two major problems are facing the industry, namely, the low filtration rate of the acid from solid gypsum and the second is the high level of impurities which decreases the $\mathrm{P}_{2} \mathrm{O}_{5}$ water solubility of the produced fertilizers. The filtration rate has been doubled by utilization of surface active agents (Surfactants) to modify the gypsum crystals. On the other hand, novel technique is being developed to decrease the impurities especially iron from $4 \%$ to $<1 \%$ leading to increasing the $\mathrm{P}_{2} \mathrm{O}_{5}$ water solubility of the produced fertilizer. Further decrease of $\mathrm{Fe}$ content of the fertilizer grade acid to $<0.1 \%$ is achieved through application of a novel membrane technology. The purified acid could be used for food and pharmaceutical industries, thus the economics of the acid production units greatly improve. The paper reviewed the results obtained so far which will improve significantly the value added products. The effects of the different parameters such as oxalic acid dose, temperature and concentration of phosphoric acid on $\mathrm{Fe}_{2} \mathrm{O}_{3}$ removal efficiency

have been studied. Increasing the oxalic acid dose up to $7.5 \mathrm{~g} / 100 \mathrm{~g}$ of $28 \% \mathrm{P}_{2} \mathrm{O}_{5}\left(80{ }_{\circ} \mathrm{C}, 100\right.$ rpm) raised the removal efficiency of $\mathrm{Fe}_{2} \mathrm{O}_{3}$ to $90.8 \%$. Increasing the dose of oxalic acid to 10 $\mathrm{g} / 100 \mathrm{~g}$ led to slight increase in the removal efficiency of $\mathrm{Fe}_{2} \mathrm{O}_{3}$ to $91.6 \%$.
\end{abstract}

1. Central Metallurgical R\& D Institute (CMRDI)

2. Cairo University

3. Department of Chemistry, Faculty of Science, Ain Shams University 